\title{
ANÁLISE HISTÓRICA DA NORMA DO PACIFISMO NA CONSTITUIÇÃO DO JAPÃO
}

\author{
HISTORICAL ANALYSIS OF CLAUSE OF PACIFISM IN THE \\ CONSTITUTION OF JAPAN
}

\author{
Rodrigo Luís Kanayama* \\ Eduardo Mesquita Pereira Alves**
}

\begin{abstract}
RESUMO: A cláusula pacifista presente na Constituição do Japão é causa de intenso debate desde a época de sua elaboração. A sua difícil interpretação, na doutrina e jurisprudência japonesas, vem provocando efeitos concretos. Discute-se a capacidade do Japão em possuir armamentos militares, ou se pode se autodefender de ataques externos, ou se pode manter forças de autodefesa. Suscitou-se o problema em apreciação judicial, sem conclusão, contudo. Neste trabalho, estudou-se a formação da Constituição do Japão e foram analisadas as decisões judiciais referentes ao tema, a fim de expor os obstáculos interpretativos da norma pacifista. Entende-se, finalmente, que a cláusula pacifista deve ser interpretada restritivamente, ou seja, é garantido o direito de autodefesa do Estado japonês.
\end{abstract}

PALAVRAS-CHAVE: Direito Constitucional. Constitucionalismo japonês. Pacifismo. Renúncia à guerra. Autodefesa.

ABSTRACT: The pacifist clause of the Constitution of Japan is cause of intense debate since its formulation. The difficulties of interpretation found in Japanese doctrine and jurisprudence has produced concrete effects. The possibility of Japan keeping military firepower, defending itself from external attacks and the maintenance of a self-defense force is subject of many debates. The Judiciary Branch has appreciated the problem, although without any conclusions. This paper studies the shaping of the Constitution of Japan and uses the analysis of judicial decisions regarding the target issue as means of exposing the pacifist clause's interpretative obstacles. This article concludes that the clause of pacifism must be interpretated restrictively. in other words, the Japanese right of self-defense must be granted.

KEYWORDS: Constitutional Law. Constitutionalism of Japan. Pacifism. Renunciation of war. Self-defense.

* Advogado, Doutor em Direito do Estado - UFPR, Professor do Departamento de Direito Público (Direito Financeiro) da Faculdade de Direito-UFPR. E-mail: rodrigo@kanayama.adv.br.

**Advogado, Bacharel em Direito pela Faculdade de Direito - UFPR. E-mail: eduardompa@, gmail.com.

Este trabalho foi escrito em conjunto, pelos dois autores. Em primeiro lugar, é resultado da pesquisa realizada pelo acadêmico Eduardo Mesquita Pereira Alves, quando morou em Tóquio, Japão. São de sua autoria as traduções do japonês ao português. O Prof. Rodrigo Luís Kanayama foi responsável por orientá-lo e, para publicação do artigo, redigiu parte do texto e incluiu artigos jurídicos, promovendo a organização do texto. 


\section{INTRODUÇC̃̃̃}

Desconhecido no Ocidente, o Direito japonês é rico em debates e teorias constitucionais. Promulgada sob influência ocidental, especificamente norteamericana, a Constituição do Japão pós-guerra desperta a curiosidade dos estudiosos de Direito Constitucional no tocante ao seu preâmbulo e art. $9^{\circ}$, ambos relacionados ao dever de paz do Estado japonês.

Após a Segunda Guerra Mundial, os norte-americanos ocuparam o Japão e impuseram normas em sua Constituição e, visando à retirada nipônica de conflitos armados, incluíram cláusula proibitiva de guerra. Embora, aparentemente, seja uma norma de exclusão de todo e qualquer conflito armado (a proibição se estende a possuir armas), o Japão enfrentou situações em que se discutiu a necessidade de autodefesa. Debates foram travados em controle de constitucionalidade sobre o alcance da norma sem, no entanto, a obtenção de resultado definitivo.

O impasse sobre a interpretação da cláusula pacifista japonesa revela problemas. Em primeiro lugar, a forte influência - ou seria, simplesmente, "imposição" - norte-americana, que eliminou vontade soberana japonesa; em segundo, a dificuldade do enfrentamento de questões concretas face a uma norma extremamente restritiva, a ponto de impedir - ou tentar impedir - até mesmo movimentos de autodefesa.

Diante das dúvidas que giram em torno da Constituição do Japão, e pela riqueza na interpretação histórica e jurídica do instituto que veda a guerra, farse-á análise a partir do momento do final da Segunda Guerra Mundial, apreciandose decisões judiciais relacionadas ao tema.

No que tange à análise histórica do processo de elaboração da Constituição de 1947, o uso de autores americanos tem sua razão no fato de se tratarem muitas vezes de fontes primárias, redatores originais ou acadêmicos que acompanharam com maior proximidade os acontecimentos que deram origem ao texto produzido durante a Ocupação Aliada após a Segunda Guerra Mundial. Já na análise do art. $9^{\circ}$, por outro lado, privilegiou-se a doutrina japonesa, em uma tentativa de mostrar a forma específica pela qual os juristas do país interpretam seu ordenamento constitucional. Ainda que existam traduções em inglês do texto legal e de alguma parcela da doutrina, no presente estudo utilizou-se material no idioma japonês, com tradução livre, na tentativa de tentar a melhor adaptação da linguagem jurídica japonesa diretamente ao vernáculo, mantendo a fidelidade às opiniões de cada autor. Tal método possibilitou não apenas a interpretação sistemática ou histórica do dispositivo, mas também sua exegese literal. 


\section{A CONSTITUIÇÃo do JAPÃo E O PACIFISMo}

Nós, o povo japonês, agindo através de nossos representantes legitimamente eleitos, determinados a garantir, para o presente e para a posteridade, os frutos da cooperação pacífica e as bênçãos da liberdade por toda a ilha, e decididos a nunca mais deixar que os horrores da guerra ocorram através de ações do governo, proclamamos que a soberania reside no povo, e firmemente estabelecemos essa Constituição. O governo é uma instituição sagrada do povo, sua autoridade deriva do povo, seus poderes são exercidos pelos representantes do povo, o bem-estar é usufruído pelo povo. Esse é um princípio universal da humanidade no qual se funda a Constituição. Nós rejeitamos todas as constituições, leis e decretos que o contrariem. O povo japonês deseja de todo coração a paz eterna, conscientes dos elevados ideais que regem as relações humanas, e, determinados a preservar nossa segurança e existência, confiamos na justiça de todos os povos que amam a paz. Nós desejamos ocupar um lugar de honra em uma sociedade internacional que busca a preservação da paz e a extinção do despotismo, escravidão, opressão e intolerância. Nós reconhecemos que todos os povos do mundo têm direito a uma existência pacífica livre de medo e necessidade. Nós acreditamos que nenhuma nação deve se devotar apenas a si mesma, ignorando os outros países, devendo seguir os princípios da moralidade política universal, mantendo a própria soberania, em seu dever na construção de uma relação de igualdade com as demais nações. $O$ povo japonês jura, em nome da honra nacional, atingir esses elevados objetivos e ideais. (Preâmbulo da Constituição do Japão - Nihonkoku Kenpou).

Essas são as palavras que iniciam a Constituição do Japão. O preâmbulo salienta a convivência pacífica, definindo "paz eterna" como desejo do povo japonês. Embora não seja adequado afirmar, peremptoriamente, que o preâmbulo possui força normativa, traz o espírito da Constituição e do povo. É a introdução ao texto normativo e delimita sua área de interpretação.

A Constituição do Japão, que hoje ainda vige, nasceu em 1947, fruto do desfecho da Segunda Guerra Mundial. Ainda que formalmente seja considerada como reforma ou revisão da Constituição anterior (da Constituição Meiji), não manteve as cláusulas pétreas ou continuidade constitucional material. O espírito dessa nova Constituição consagra princípios democráticos e pacifistas, ao contrário da precedente. ${ }^{1}$

Explica John M. Maki sobre a nova Constituição que "a teoria constitucional japonesa é construída na proposição de que pacifismo, soberania popular, e a

1 A Constituição Meiji foi promulgada em 11 de fevereiro de 1889 com o nome de Constituição do Grande Império Japonês, revelando-se uma combinação de tecnologia política ocidental e ideias políticas tradicionais japonesas. Estabeleceu-se uma monarquia constitucional, com o imperador legalizado como monarca absoluto e sagrado, acima do governo e corpo de Estado. Foi uma Constituição imposta, sem conhecimento do povo. (Cf. COLEGROVE, 1937, p. 1046-1049 e KOBAYASHI, 2006, p. 23). 
garantia de direitos humanos fundamentais são as fundações da Constituição". Para o autor, é bastante peculiar o pacifismo como princípio constitucional, porém reconhece que tem o direito de estar na posição de princípio fundamental (MAKI, 1990, p. 73). Nesse sentido, vem o art. $9^{\circ}$ da Constituição do Japão (o qual é encontrado no Capítulo 2, que possui apenas um artigo):

Capítulo 2 - Renúncia à Guerra

(Renúncia à guerra e negação ao potencial de guerra e direito de beligerância)

Art. $9^{\circ}-O$ povo japonês, aspirando sinceramente por uma paz internacional baseada na ordem e na justiça, renuncia eternamente à guerra como direito soberano do Estado, e a ameaça ou uso de poder armado como meio de resolução de conflitos.

Para atingir o objetivo do parágrafo precedente, nenhuma espécie de potencial bélico ou força aérea, marítima ou terrestre será mantida. O direito de beligerância do Estado não será reconhecido. ${ }^{2}$

A partir dessa norma constitucional, retiram-se as seguintes interpretações: (a) o Japão renuncia à guerra (e o uso da força) como instrumento para dirimir disputas internacionais; (b) fim da manutenção de forças bélicas; (c) não reconhecimento do direito à guerra. Saber de que forma e porque o Japão incluiu essa norma como fundante do Estado requer uma breve retrocessão temporal (MAKI, 1990, p. 73-74).

\section{A CONSTITUIÇÃo DO JAPÃo DE 1947: DEBATES SOBRE A INCLUSÃo DA CLÁUSULA PÁCIFISTA}

Ao final da Segunda Guerra Mundial, com a rendição do Japão, a base da nova Constituição japonesa foi lançada pela Declaração de Potsdam, documento assinado em 26 de julho de 1946 por Harry Truman, Winston Churchill e Chiang Kai-Shek. Tal declaração atestou a rendição incondicional do Japão e, principalmente, determinou-se o rumo que o país deveria seguir. $\mathrm{O}$ objetivo era extinguir a antiga ordem que levou o Japão às guerras de conquista, a partir da restauração da democracia, respeito aos direitos fundamentais e à liberdade do povo, extinção do caráter divino do Imperador, bem como comprometer o Estado japonês a adotar uma postura pacífica pela democratização e desmilitarização. $\mathrm{O}$ auxílio para o intento veio do Quartel General da Ocupação Militar Americana

\section{2 第 2 章戦争の放棄}

戦争の放棄と戦力及び交戦権の否認」第 9 条日本国民は、正義と秩序を基調と寸る国際平 和を誠実に希求し、国権の発動たる戦争と、武力による威嚇又は武力の行使は、国際紛争を解決す る手段としては、永久にこれを放棄する。前項の目的を達するため、陸海空軍その他の戦力は、 これを保持しない。国の交戦権は、これを認めない。 
(também nomeado de Ocupação), chefiado pelo Comandante Supremo dos Poderes Aliados (SCAP) ${ }^{3}$, General Douglas MacArthur (KADES, 1989, p. 217) ${ }^{4}$.

A Constituição Meiji era um obstáculo na concretização de uma nova ordem. Foi estabelecido, em outubro de 1945, o Comitê de Investigação das Questões Constitucionais (憲法調査問題委員会), ou Comitê Matsumoto, para examinar a questão da revisão, ainda que sob oposição das autoridades japonesas, representadas naquele momento da Ocupação pelo Gabinete do Primeiro-Ministro Kijuurou Shidehara.

Diferente da Constituição Meiji, a nova Constituição não foi objeto de outorga imperial. Não foi elaborada por um grupo de estudiosos do Direito ou por uma Constituinte especificamente formada para tanto, restando nas mãos da Dieta $^{5}$ a discussão do projeto a ser apresentado pelo Comitê Matsumoto, em ambas as casas - a Câmara Baixa, eleita pela população, e a Câmara dos Nobres, indicados pelo imperador (KADES, 1989, p. 217).

Enquanto o Gabinete de Shidehara discutia a nova Constituição - a partir do rascunho elaborado pelos Estados Unidos - o ministro do bem-estar, Hitoshi Ashida, levantava importante questão: se no passado o Japão não cumprira o Pacto Kellog-Briand (de 1928, chamado de Pacto de Paris, de renúncia à guerra), nesse momento não seria tão radical prever a proibição da guerra na própria Constituição. Os Estados Unidos já haviam declarado que o objetivo da guerra era desarmar os países agressores. Tal visão foi reforçada na cerimônia de rendição, em 29 de agosto de 1945, na qual o Presidente Truman informou o General Douglas MacArthur (SCAP) que o Japão não poderia mais ser uma "ameaça para os Estados Unidos ou para a paz e segurança do mundo", devendo ser completamente desmilitarizado. $^{6}$

3 Segundo Ward, "SCAP stands for Supreme Commander for the Allied Powers. The term is used to refer individually to either General MacArthur or General Ridgeway, the two occupants of this office, and collectively to the General Headquarters that they commanded." (WARD, 1965, p. 402).

4 Não foi a primeira vez que o Japão ingressou em um tratado de paz ou de renúncia à guerra. Em 1928, o Japão aderiu ao Pacto de Paris, também chamado de Kellog-Briand 'Tratado Geral para a Renúncia à Guerra'. A guerra tornou-se instrumento que não poderia ser adotado nas relações entre os países. Mesmo assim, a despeito da vigência do Pacto de Paris, em 1931 o Japão invadiu e ocupou a Manchúria, na China e, em 1941, atacou Pearl Harbor (McNELLY, 1962, p. 351).

5 Dieta (国会): Parlamento Bicameral Japonês.

6 "A primeira grande tarefa da Ocupação Aliada do Japão foi desarmar completamente o país. Soldados japoneses a marinheiros foram trazidos para casa. Todo tipo de arma, incluída as espadas dos antigos samurais, foram confiscadas pelas forças americanas. Fábricas capazes de produzir material bélico foram fechadas. $O$ único ciclotron japonês em fase experimental foi destruído" (McNELLY, 1962, p. 353). 
A dúvida sobre o alcance da cláusula do desarmamento remanesceu nas discussões sobre a elaboração da nova Constituição. O próprio Departamento de Estado Americano, aparentemente, não acreditava que a cláusula seria necessária na Constituição japonesa (McNELLY, 1962, p. 354-355). A mesma opinião detinha o Comitê de Coordenação Estado-Guerra-Marinha (SWNCC), também americano, que previa uma profunda alteração da formação do governo japonês, caso se incluísse a cláusula pacifista na Constituição (McNELLY, 1962 , p. 356-358).

A seção do governo do SCAP, em dezembro de 1945 e janeiro de 1946, tornou-se diretamente interessada pela elaboração da Constituição e procedeu a estudos de variadas propostas de emenda feitas por cidadãos japoneses, partidos políticos e grupos privados. Novamente, não se notava a necessidade da cláusula pacifista na nova Constituição (McNELLY, 1962, p. 356).

O Primeiro-Ministro Shidehara compareceu a uma conferência com o General MacArthur, em 24 de janeiro de 1946. Segundo Theodoro McNelly, aparentemente o art. $9^{\circ}$ nasceu nessa reunião. Shidehara sempre teve como desejo, desde a assunção a seu cargo, evitar que o Japão se envolvesse em outra guerra. Aliás, surgiu entre os Aliados o desejo de extinguir o governo imperial japonês e, para evitar que isso ocorresse, ou seja, para que o Imperador se tornasse aceitável, Shidehara redigiu um rascunho de discurso, em 1946, no qual Hirohito renunciava seu caráter de divindade; no mesmo ato, renunciava à guerra. Se Shidehara era contrário à extinção do direito à guerra, isso não ficou claro no discurso Matsumoto, ao contrário, manifestava descontentamento com a proposta (McNELLY, 1962, p. 360-361).

Sem realizar qualquer consulta à população ou à Ocupação, o Comitê Matsumoto esboçou uma nova Constituição, divulgada no jornal Mainichi Shinbun em 1946, no qual apenas dois artigos haviam sido modificados em relação à Constituição Meiji: o $3^{\circ}$, com a exclusão da palavra "sagrado", retirando a previsão constitucional do caráter divino do imperador ${ }^{7}$, e o art. 11, com a retirada do ideograma que designa "exército". ${ }^{8}$

7 Art. $3^{\circ}$ - O Imperador é sagrado e inviolável. (第3条天皇ハ神聖ニシテ侵スヘカラス).

8 Art. 11 - O imperador é o comandante supremo da marinha e do exército. (第 11 条天皇八陸海 軍习統帥). Aqui existe barreira idiomática difícil de transpor. O ideograma exército junto dos ideogramas terra e mar forma expressão que engloba marinha e exército, como instituições formais, sua retirada e substituição por outra manteria o imperador como comandante de algum tipo de força armada, mas que formalmente não seria designada como exército, e, portanto, de alguma forma representaria uma resposta à exigência de desmilitarização. 
A proposta do Comitê Matsumoto foi recusada pelo Quartel General da Ocupação em 8 de fevereiro de 1946 e, acusando a falta de vontade de estabelecer uma Constituição democrática por parte do governo, Douglas MacArthur ordenou que os projetos de Constituição deveriam incluir os seguintes princípios: abolição da soberania do Imperador; renúncia à guerra e proibição da manutenção de forças armadas, inclusive para fins de defesa; e fim do feudalismo, com a extinção de privilégios da nobreza, bem como inclusão do sistema inglês como modelo de elaboração de orçamento (McNELLY, 1992, 592). Não havia alternativa: para salvar o trono japonês (o Imperador), fazia-se necessária a inclusão da cláusula do pacifismo na Constituição. A hesitação do governo japonês levou o Quartel General a encampar a tarefa de elaboração do texto constitucional, o que foi feito pelos especialistas americanos da Seção de Governo em uma semana.

Encaminhado tal texto para a Dieta, as matérias mais debatidas foram o Imperador enquanto símbolo e a renúncia à guerra. A maior preocupação era a de que, ao mesmo tempo, o Japão renunciaria à guerra e à autodefesa. $\mathrm{O}$ temor foi externado pelo então Presidente do Comitê da Reforma Constitucional da Câmara dos Representantes, Hitoshi Ashida, que propôs emenda ao art. $9^{\circ}$ (McNELLY,1962, p. 369). A controvérsia permaneceu - problemas interpretativos referentes à capacidade de autodefesa ou de rearmamento para fins de defesa.

MacArthur deu liberdade à Dieta para lidar com o problema apresentado; deixou claro que era permitido ao Poder Legislativo aceitar, modificar ou recusar o Projeto caso entendesse necessário. Interessante observar que a mesma opção não havia sido dada ao Gabinete (McNELLY, 1992, p. 595). Isso ocorreu pela provável existência de uma genuína preocupação do General com a aprovação democrática do texto constitucional pelos legisladores representantes do povo, e não por burocratas do Poder Executivo.

Apresentado à Dieta, o projeto sofreu pequenas mudanças nas duas casas legislativas para adequação às exigências da Comissão, reforçando a soberania residente no povo e não no Imperador (art. $1^{\circ}$ ), acrescentando a seleção do Primeiro Ministro e do Gabinete pela Dieta (art. 67), atribuindo o status civil aos membros do Gabinete (art. 66), sufrágio universal (art. 15) e transferência da propriedade da Casa Imperial ao Estado (McNELLY, 1992, p. 593). Assumiu sua forma definitiva em 7 de outubro, com acréscimos relevantes ao art. $9^{\circ}$ pelo então Parlamentar Ashida Hitoshi.

A Constituição foi promulgada em 3 de fevereiro de 1947 e entrou em vigor 3 de maio de 1947 com o nome de Nihonkoku Kenpou, que, diferente da Constituição 
do Grande Império Japonês, significa apenas Constituição do Japão, mantendo-se intacta até hoje. ${ }^{9}$

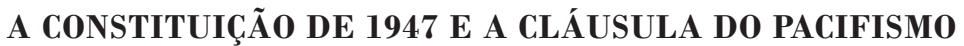

Foi novidade uma Constituição com previsão de renúncia à guerra em moldes tão extensos como da lei japonesa ${ }^{10}$. Como afirmava Harold S. Quigley, "não se renunciou à autodefesa, mas ela seria ineficaz sem forças militares de qualquer tipo" (QUIGLEY, 1947, p. 869). Em outras palavras, mesmo que se mantivesse a faculdade de se autodefender, ela não poderia ser exercida, pois os instrumentos não existem.

Para compreender a contradição aparente entre uma renúncia à manutenção de forças militares e a existência, nos dias de hoje, de um exército de fato no Japão, é preciso decompor o art. $9^{\circ}$ e analisar o significado preciso de cada expressão nele prevista.

Iniciando pelo caput do art. $9^{\circ}$, a renúncia está objetivamente contida na asserção de que o povo japonês "... renuncia eternamente à guerra como direito soberano do Estado, e a ameaça ou uso de poder armado...". Em um cotejo com as leis internacionais, especialmente com a Carta das Nações Unidas, emerge a primeira constatação conclusiva quanto à amplitude das restrições impostas ao direito de beligerância do Estado Japonês. Estão constitucionalmente proibidas as guerras definidas pelo Direito Internacional como os conflitos nos quais há uma declaração formal que expõe o animus belligerandi (significado stricto sensu da palavra guerra), bem como as guerras de fato, situações nas quais não há tal declaração, mas há um uso de poder armado.

9 "A Constituição presente [1947] [...] foi proclamada pelo Premier Yoshida Shigeru na presença de Hirohito [o Imperador] em 3 de maio de 1947. A proclamação foi lida de uma plataforma no Palace Plaza em Tóquio. A audiência de cinco mil pessoas que permaneceram na chuva ante a plataforma era pequena em comparação com a grande multidão que acompanhou a carruagem imperial em 3 de novembro de 1946 , na sequência da cerimônia oficial de promulgação; mas foi igualmente entusiasmada na demonstração de sua lealdade. Nas duas situações, aparentemente foi que o aparentemente tímido, pequeno Imperador com óculos, e não a Constituição, era o centro do interesse popular" (QUIGLEY, 1947, p. 865, tradução livre).

${ }^{10}$ A Constituição japonesa não foi a primeira a declarar a paz como princípio ou diretriz constitucional, e também não foi a primeira a proibir guerras de invasão. Nesse sentido, podemos observar a Constituição Francesa de 1791 em seu Título IV, e a própria Constituição brasileira de 1891 é apontada pioneira no tema. No século XX, posição semelhante foi adotada pelas Constituições espanhola (1931), italiana (1947), alemã ocidental (1947), coreana (1948), tailandesa (1949), entre outras. O que diferencia a Constituição japonesa de 1947 é o fato de nascer com a renúncia a qualquer tipo de guerra, seja ela de invasão ou de defesa, proibindo a manutenção de qualquer tipo de forças armadas e armas. 
A proibição de ambas as formas de guerra se torna especialmente relevante em um país que por duas vezes invadiu nações vizinhas sem declaração formal, e, portanto, sem constituição formal do estado de guerra: em 1931 no incidente da Manchúria, e em 1937 quando ocupou a China, escapando, assim, das restrições previstas no Pacto Kellogg-Briand (KASUYA, 1986, p. 29).

Um olhar mais atento, entretanto, revela que existe uma ampliação com relação às proibições previstas na Carta da ONU. Tal ampliação se materializa na expressão "ameaça". A ameaça de uso de força já estava presente no Pacto da Liga das Nações ${ }^{11}$, como situação que interessaria a toda a Liga, mas não figurou nos tratados posteriores como uma restrição ao direito de beligerância.

Logo, pela redação atual do art. $9^{\circ}$, até mesmo o uso de ultimato com intenções bélicas está proibido pela Constituição, ampliando a renúncia à guerra de forma ainda não vista formalmente no Direito Internacional, passando a abranger atos preparatórios ao uso da força, e a mera manifestação da intenção de seu uso. Conclui-se que, mais do que o estado de guerra, a simples ideia de guerra resta constitucionalmente limitada.

Além das restrições vistas até agora, o caput do art. $9^{\circ}$ acrescenta, ainda, a renúncia à ameaça ou uso de poder armado "como meio de resolução de conflitos", ou seja, o texto constitucional além de definir o objeto da limitação, condiciona a existência da proibição a uma finalidade determinada. É na seara da finalidade da guerra que o debate se amplia e surge a principal polêmica, qual seja, se a determinação constitucional diz respeito apenas às guerras de invasão ou também à autodefesa.

Para os que acreditam que a guerra como meio de resolução de conflitos internacionais significa a proibição de guerras de defesa, bem como de invasão, prevalecem três argumentos (KASUYA, 1986, p. 31): primeiramente, todas as guerras entre nações teriam como premissa a resolução de um conflito internacional e, dessa forma, a guerra de autodefesa também seria uma forma de resolução desses conflitos.

11 Quando tratamos sobre conflitos armados que não chegam a constituir o estado de guerra, analisamos espécie que se tornou comum especialmente após a Primeira Guerra Mundial. Em face dinâmica nas Relações Internacionais após o conflito, o tratamento dado ao tema sofreu as primeiras modificações visíveis no Pacto da Liga das Nações. O início do art. 11 do Pacto da Liga das Nações, aprovado na Conferência de Versalhes em 1919, estabelece o princípio geral da Liga, segundo o qual: "[...] Fica expressamente declarado que toda guerra ou ameaça de guerra, quer afete diretamente ou não um dos Membros da Liga, interessará à Liga inteira e esta deverá tomar as medidas apropriadas para salvaguardar eficazmente a paz das Nações [...]". 
Como segundo argumento, qualquer guerra pode ser denominada como guerra de defesa ou legítima defesa, na medida em que a justificativa de uma guerra de invasão pode ser, por exemplo, a manutenção da soberania de uma nação. Nesse sentido, a separação entre os dois tipos de guerra é muito tênue e não seria prudente aceitar uma leitura constitucional tão vaga.

Por fim, se a guerra de defesa fosse reconhecida pelo sistema constitucional, a Constituição apresentaria algum tipo de previsão ou regulação do exército ou qualquer organização militar. Ocorre que a Constituição Japonesa é silente sobre o tema. A única referência indireta, que pode ser inferida contrario sensu, é a presença da palavra "civil" ${ }^{12}$, em sua conotação oposta à militar, no art. $66^{13}$. Sendo a Constituição o documento que fundamentalmente organiza as funções do Estado, alguns autores veem a previsão constitucional como condição absoluta para a manutenção de um exército (NISHI, 1978, p. 17).

Apesar de bastante lógica, tal opinião é frágil. Não resiste ao cotejo com o Direito Comparado e nem com a intenção do legislador. É forçoso observar que Pacto Kellogg-Briand já trazia a proibição ao "recurso à guerra para a solução das controvérsias internacionais" em seu art. $1^{\circ}$, e tal disposição nunca foi interpretada de forma a restringir guerras defensivas.

Por sua vez, Charles L. Kades, o principal responsável pela redação e inclusão do art. $9^{\circ}$ na Constituição Japonesa, afirmou em entrevista que o Pacto de Paris o havia influenciado na tarefa (KADES, 1981, p. 68), de forma que se faz possível interpretar o referido artigo com base no Pacto. Qualquer interpretação no sentido de não reconhecimento do direito de legítima defesa no caput do art. $9^{\circ}$ seria muito mais ampla do que as interpretações dadas ao tratado que o fundamenta e inspira, e, nesse sentido, difícil de ser sustentada frente à sistemática que originou o dispositivo (KASUYA, 1986, p. 36).

Até aqui a renúncia à guerra imposta ao Japão ainda é muito nebulosa. A princípio, o caput não traz proibição definitiva ao direito de autodefesa, logo, é no parágrafo único do art. $9^{\circ}$ que se encontra a principal brecha na proibição que em uma primeira leitura parecia absoluta. $O$ parágrafo único estabelece os meios pelos quais os objetivos do caput serão atingidos. Na redação original do art. $9^{\circ}$, não existia, no entanto, essa meta-referência, e o próprio caput era muito mais sucinto do que em sua versão definitiva.

12 Importante destacar que palavra civil (bunmin - 文民), como oposta a militar, não existia no idioma japonês, e precisou ser criada por especialistas do Parlamento no período de debates e revisão antes da promulgação da Constituição (KADES, 1989, p. 240).

${ }^{13}$ Art. $66[\ldots]$

(2) O Primeiro Ministro e os outros Ministros de Estado devem ser civis. 
$\mathrm{O}$ art. $9^{\circ}$ se inicia com a seguinte frase: "O povojaponês, aspirando sinceramente por uma paz internacional baseada na ordem e na justiça". Tal construção não estava no esboço original da Reforma Constitucional de 1946. A redação inicial do General Douglas McArthur e redigida pelo General Kades apresentava a seguinte formatação:

Art. $9^{\circ}$ - A guerra como direito soberano da nação, e a ameaça ou uso de poder armado, são renunciados eternamente como meios de solução de conflito com outras nações.

A manutenção de força terrestre, aérea ou marítima, bem como outros potenciais de guerra, nunca será autorizada. O direito de beligerância do Estado não é reconhecido.

O texto foi modificado pela Dieta em 24 de agosto de 1946, passando a figurar com a redação em japonês atual. ${ }^{14}$ As modificações foram introduzidas pelo parlamentar Ashida Hitoshi, que apresentou como razões para o acréscimo da frase "aspirando sinceramente por uma paz internacional baseada na ordem e na justiça" no caput, a intenção de deixar claro que a renúncia a guerra e a remoção de qualquer tipo de exército tinham por objetivo dar início ao ideal de paz mundial e cooperação da humanidade previsto no preâmbulo (KENPOU CHOUSAKAI, 1952, p. 58-62).

Na reunião do Comitê de Investigação da Reforma Constitucional da Câmara dos Representantes, Ashida afirmou que a modificação buscava deixar clara a assunção pelo povo japonês, com entusiasmo, de uma postura vanguardista no sentido de promoção da paz mundial e desmilitarização (TANAKA, 1987, p. 106). Dessa forma, politicamente, "objetivos do parágrafo precedente", expressão que inicia o parágrafo único, deve ser entendida como referência ao trecho do caput "aspirando sinceramente por uma paz internacional baseada na ordem e na justiça" (KASUYA, 1986, p. 58).

Entretanto, o próprio autor da emenda modificou a interpretação, não por coincidência, após o Pacto de Segurança com os Estados Unidos e a criação das Forças de Autodefesa, e no que tange a esse tema em específico, declarou ao Mainichi Shinbun, em 1951, que o objetivo a que se refere o parágrafo único é a vedação ao uso da guerra como política de Estado e como forma de resolução de conflitos internacionais ${ }^{15}$, que, como já foi demonstrado, são ideias aptas a excluir a proibição ao direito de defesa.

${ }^{14}$ Curiosamente, a nova redação em inglês não correspondia à exata tradução do japonês, mostrando-se menos restritiva com relação à guerra a ao uso de potencial bélico, fomentando discussões que não serão aqui levantadas por terem origem em mero erro de tradução (ITSUNOMIYA, 1969, p. 180).

15 Mainichi Shinbun, 14/01/1951. 
Nesse sentido, o próprio redator do artigo, Kades, afirmou que o direito de autodefesa era natural de qualquer Estado soberano. Atuou, inclusive, ativamente na defesa desse direito. A redação inicial do art. $9^{\circ}$, modificada pela Reforma Ashida, já era versão modificada por Kades a partir da proposta inicial do General Douglas McArthur, da qual se lia:

Art. $9^{\circ}$ - $\mathrm{O}$ direito soberano da nação à guerra é abolido. $\mathrm{O}$ Japão renuncia a esse direito como instrumento para a resolução de disputas e até mesmo para preservação de sua própria segurança.

Kades, acreditando que tal dispositivo era irreal, modificou sua redação, de forma a suprimir a renúncia ao direito de uso da guerra para preservação da própria segurança, ainda que contra a vontade do General Whitney, mas restou, ao fim, legitimado pela própria concordância de McArthur (KADES, 1989, p. 236).

Dessa forma, o parágrafo único do art. $9^{\circ}$ sedimenta o entendimento de que a cláusula pacifista não inclui a proibição extensiva à autodefesa. Além das posições políticas e legislativas, nesse sentido também existe apoio doutrinário. Para Kiichirou Yasuzawa, o objetivo do caput do art. $9^{\circ}$ é a renúncia às guerras de invasão, materializada na renúncia à guerra como meio de resolução de conflitos na exata medida da interpretação conferida ao caput individualmente, ou seja, o conteúdo da segunda parte do artigo deveria coincidir com a primeira, e se esta não reconhece a renúncia ao direito de autodefesa, também não o faz aquela (YASUZAWA, 1981, p. 162-63). ${ }^{16}$

Resta, portanto, definir qual o critério diferenciador entre uma força armada apta à invasão e uma força defensiva, o que será feito pela delimitação dada pela expressão potencial bélico como núcleo objetivo da proibição do parágrafo único do art. $9^{\circ}$.

Potencial bélico é um termo vago, sujeito a diversas interpretações, carecendo de uma definição única que encerre um sentido definitivo, motivo pelo qual merece atenção especial para a compreensão das prescrições previstas no art. $9^{\circ}$ da Constituição japonesa. Shizuo Itsunomiya define o potencial bélico como a capacidade de "executar" a guerra, sem questionar se é a partir da capacidade humana ou de qualquer outro meio físico, sem distinguir se essa capacidade é usada para a manutenção da ordem interna ou qualquer outro fim, não importando se

${ }^{16}$ Em sentido contrário, Yuuichi Takano e Yasuzou Suzuki (TAKANO, 1964, p. 154; SUZUKI, 1956, p. 77), são representativos do entendimento de que a existência da menção à aspiração a paz internacional baseada na ordem e na justiça pressupõe a renúncia à guerra, ao uso de poder armado, à ameaça do uso de poder armado e ao uso destes como meio de resolução de conflitos. 
esse poder é existente ou latente (ITSUNOMIYA, 1969, p. 180). Tal definição é, entretanto, muito ampla e, dentro dessa visão, é possível considerar, por exemplo, aeroportos, portos, instituições de polícia ostensiva e repressiva como elementos constituintes de um potencial bélico (KASUYA, 1986, p. 42). Dessa forma, a definição não é comumente aceita, mas não é despida de relevância, na medida em que revela a amplitude que pode ser atribuída ao conceito.

Parece apropriado, portanto, que qualquer definição leve em conta em primeiro lugar o objetivo principal do potencial de guerra, qual seja, a manutenção da ordem externa de um país, em oposição à função da polícia, que é a manutenção da ordem interna. A distinção foi discutida no Comitê de Reforma Constitucional da Câmara dos Lordes em 1946 (KENPOU CHOUSAKAI, 1952, p. 58-62), chegando à conclusão de que, apesar de ambas as instituições possuírem equipamentos que podem ser utilizado para fins bélicos, a forma e a escala de uso diferem fundamentalmente.

Implica, portanto, em dizer que não apenas a manutenção das instituições formais da marinha, aeronáutica e exército é proibida, mas qualquer tipo de força ou organização que a elas seja equivalente, ou que de alguma forma tenha a manutenção de potencial bélico suficiente para agressão externa, ou, ainda que possa ser convertida a essa função (KASUYA, 1986, p. 45). Ou seja, o potencial latente também é proibido (SATOU, 2001, p. 118).

Vistas de forma geral, mas não exaustiva, das interpretações possíveis do art. $9^{\circ}$, observa-se que o único consenso parece ser no sentido de que o caput proíbe, no mínimo, as guerras de invasão, e o parágrafo único proíbe a manutenção de potencial bélico que possibilite essa espécie de confronto, independentemente do que se define como objetivo do caput.

Essa seria a interpretação mais conservadora, e ao longo dos anos tem sido adotada pelo Poder Executivo e pelos Tribunais Superiores japoneses, como será visto adiante. Entretanto, também fica claro que outras interpretações são possíveis, seja pelos métodos de hermenêutica jurídica empregados, seja pelos ideais ou interesses que pautem a atividade interpretativa.

\section{A AUTODEFESA E AS CONTROVÉRSIAS CONSTITUCIONAIS}

De acordo com o que foi demonstrado até aqui na seara hermenêutica, a cláusula do pacifismo não permaneceu incólume por muito tempo após sua introdução no ordenamento jurídico japonês. Em junho de 1950, três anos após o nascimento da nova Constituição, a guerra da Coreia promoveu a primeira relativização do art. $9^{\circ}$ (MAKI, 1990, p. 74). 
Conforme narra John M. Maki, o Japão foi encorajado a mitigar a cláusula do pacifismo pelos Estados Unidos. Criou, em 1950, a Polícia Nacional de Reserva ${ }^{17}$; em 1951 firmaram, japoneses e americanos, tratado que reconheceria o direito do Japão à autodefesa e tratado em que os Estados Unidos reconheciam o direito do Japão de participar de decisões coletivas sobre segurança e de garantir sua autodefesa. Em 1952, a Polícia Nacional de Reserva se tornou Força de Segurança Nacional, juntamente com a criação da Guarda Marítima. Em 1954, foram criadas as Forças de Autodefesa, o Jieitai, com a função de proteção do Japão contra invasões diretas e indiretas, nos termos do art. $3^{\circ}$ de sua lei reguladora.

Evidentemente, após todas esses fatos, o art. $9^{\circ}$ da Constituição não pôde ser mantido - ao menos, da forma inicial (MAKI, 1990, p. 74). O Poder Executivo se apropriou das interpretações mais extensivas para garantir a manutenção do exército de fato materializado nas Forças de Autodefesa. Tentou-se, inclusive, apresentar emenda à Constituição ${ }^{18}$ para constitucionalizar de forma definitiva o Jieitai. Entretanto, a lei que disciplina o procedimento de aprovação das emendas só veio a ser promulgada em 2007, com um período de vacância, entretanto, de 2 anos, passando a vigorar apenas a partir de 2010.

Essa interpretação extensiva adotada pelo Poder Executivo foi alvo de questionamentos perante os tribunais japoneses desde o fim da Ocupação Norte-Americana. Os pronunciamentos do Judiciário foram, entretanto, pouco satisfatórios, com soluções em geral processuais ou, quando materiais, ligadas a questões indiretas ao tema.

A primeira apreciação judicial da matéria deu-se em 1952, quando foi proposta ação contra o processo de remilitarização do país. Tratou-se de espécie de Ação Direta de Inconstitucionalidade da Polícia Nacional de Reserva. No caso, a constitucionalidade da recém-criada Força foi questionada diretamente na Suprema Corte. O pedido foi apresentado pelo Partido Socialista Japonês e teve por objetivo a declaração de invalidade de todos os atos administrativos relacionados à Polícia Nacional de Reserva.

O controle de constitucionalidade judicial ainda não havia sido provocado no Japão, tendo em vista não só o pouco decurso de tempo decorrido desde a promulgação do texto constitucional, mas especialmente em face do fim recente da Ocupação Aliada, que se deu apenas em 1951.

${ }^{17}$ Polícia Nacional da Reserva (警察予備隊): organização armada japonesa, criada em 1950, que antecedeu as Forças de Preservação da Paz e as Forças de Autodefesa do Japão.

${ }^{18} \mathrm{O}$ projeto de emenda mais recente, apresentado pelo Partido Liberal Democrata pode ser visualizado na íntegra em: <http://www.kenpoukaigi.gr.jp/seitoutou/051028jimin-sinkenpousouan.pdf $>$. 
$\mathrm{O}$ argumento em defesa do cabimento do controle concentrado de constitucionalidade teve como base o art. 81 da Constituição ${ }^{19}$, partindo-se da premissa de que, estabelecendo explicitamente a Suprema Corte como última instância de julgamento no controle incidental de Constitucionalidade, seria logicamente primeira e única instância no controle abstrato de atos sob sua jurisdição. A Suprema Corte, todavia, não conheceu da ação, por unanimidade, sob o argumento de que a Suprema Corte só poderia proferir decisões em casos concretos, não cabendo o controle abstrato de leis e atos administrativos. ${ }^{20}$

As supostas violações ao art. $9^{\circ}$ foram novamente suscitadas no Caso Sunagawa (KOBAYASHI, 2006, p. 45), em 1955. Na ocasião, sete integrantes de uma manifestação contra a expansão da base americana de Tachikawa invadiram zona restrita de um complexo militar, sendo presas e denunciadas com base na Lei de Procedimentos Penais Especiais, aplicáveis a incidentes dentro de territórios utilizados pelas Forças Armadas Americanas.

A Corte Distrital de Tokyo decidiu incidentalmente no processo, em 1959, pela inconstitucionalidade do Tratado de Segurança Mútua do qual derivava a fixação de zonas militares americanas, com fundamento análogo na proibição de manutenção de potencial de guerra do segundo parágrafo do art. $9^{\circ}$, como aplicável também a tropas estrangeiras estacionadas, ainda que de forma permanente, em território japonês. Decidiu também pela inconstitucionalidade da Lei de Procedimentos Penais Especiais, que restringia direitos fundamentais a partir de procedimentos penais diferenciados da Lei Geral de Processo, inocentando todos os envolvidos. ${ }^{21}$

19 Art. 81 - A Suprema corte é a última instância com o poder de determinar a constitucionalidade de qualquer lei, ordem, regulamento ou ato oficial.

20 日本の裁判所は具体的な争訟事件が提起されないのに将来を予想して憲法及びその他の 法律命令等の解釈に対し存在する疑義論争に関し抽象的な判断を下す権限はない。

警察予備隊に係る一切の無効確認を求める訴えは不適法で却下すべきである。

(日本国憲法に違反寸る行政処分取消請求事件; 昭和 27 年(マ)第23号；民集6巻9号783頁) / "As cortes japonesas não têm autoridade para proferir decisões abstratas referentes a controvérsias de interpretação envolvendo a Constituição ou legislação infralegal quando o questionamento não se der em litígio judicial envolvendo um caso concreto. Pedido de reconhecimento da ilegalidade da Polícia Nacional de Reserva não recebido por inadequação formal" (Procedimento de Anulação de Ato Administrativo por Inconstitucionalidade, Ano 27 da Era Showa, Título 23, Repositório Civil no 6, Volume 9, p. 783, tradução livre).

21 日本政府がアメリカ軍の駐留を許容したのは、指揮権の有無、出動義務の有無に関わら ず、日本国憲法第9条2項前段によって禁止される戦力の保持にあたり、違憲である。したがって、 刑事特別法の罰則は日本国憲法第31条に違反する不合理なものである」と判定し、全員無罪の判 決を下した（東京地判昭和34.3.30 下級裁判所刑事裁判例集）/ Independentemente da existência ou não do poder de comando e disposição de tropas, o ato do governo japonês que autorizou a permanência 
Entretanto, no mesmo ano, a Suprema Corte reformou a decisão, com base na teoria dos atos de governo, entendida pelas autoridades japonesas como a impossibilidade do Judiciário de rever atos do Poder Executivo com alta carga de discricionariedade. Acrescentou, ainda, que a expressão potencial de guerra se aplica apenas às ações militares sob comando ou direção direta do governo japonês, de forma que a presença americana não ofenderia o art. $9^{\circ}$ da Constituição. A decisão final em 1963 condenou os envolvidos a uma multa no valor de dois mil ienes. ${ }^{22}$

$\mathrm{O}$ art. $9^{\circ}$ só foi questionado novamente em 1967, por ocasião do julgamento no chamado Caso Eniwa. A demanda versava sobre a instalação de campo de treinamento do Jieitai nas redondezas da cidade de Eniwa. Produtores rurais apresentaram reclamação administrativa sob o fundamento de que o som dos tiros reduzia a produtividade de leite das vacas em uma fazenda nas proximidades do campo de treinamento, em face do estresse imposto sobre os animais, de forma que foi proposto acordo no qual as Forças de Autodefesa se comprometeriam a entrar em contato diretamente com os camponeses para informá-los do início da prática de tiro.

Em dezembro de 1962, ignorando o acordo, dois irmãos proprietários de terra da região cortaram as linhas de comunicação da base, como manifestação contra a medida inócua proposta pelas autoridades, e acabaram presos e denunciados nos termos do art. 121 da Lei do Jieitai, segundo o qual:

Art. 121 - Aquele que causar dano ou destruir qualquer propriedade, arma, munição, aeronave ou outro instrumento de defesa ou equivalente das Forças de Auto Defesa será punido com a pena máxima de 5 anos e multa de até cinquenta mil ienes.

de tropas americanas viola a disposição do art. $9^{\circ}$, caput e parágrafo único, que proíbe a manutenção de potencial bélico. Ainda, a Lei Penal Especial não é razoável e viola o art. 31 da Constituição (Corte Distrital de Tokyo, Shouwa 34.3.30, Repositório Jurisprudencial Criminal dos Tribunais Inferiores).

22 「憲法第9条は日本が主権国として持つ固有の自衛権を否定しておらず、同条が禁止する 戦力とは日本国が指揮・管理できる戦力のことであるから、外国の軍隊は戦力にあたらない。した がって、アメリカ軍の駐留は憲法及び前文の趣旨に反しない。他方で、日米安全保障条約のように 高度な政治性をもつ条約については、一見してきわめて明白に違憲無効と認められない限り、その 内容について違憲かどうかの法的判断を下すことはできない」（統治行為論）として原判決を破棄 し地裁に差し戻した（最高裁大法廷判決昭和34.12.16 最高裁判所刑事判例集13・13・3225）/“O artigo $9^{\circ}$ não proíbe o direito soberano de autodefesa do Japão, o mesmo proíbe apenas a manutenção de potencial bélico pelas forças sob comando e administração japonesa, ou seja, a limitação de potencial não é aplicada às tropas estrangeiras. Dessa forma, as forças Norte Americanas estacionadas (em território japonês) não contrariam as disposições constitucionais ou preambulares. Por outro lado, tratados dotados de alto nível de natureza política, como o Tratado de Segurança Mútua entre Estados Unidos e Japão, não podem ter a constitucionalidade de seu conteúdo decidida pelo judiciário a não ser em casos de ilegalidade evidente" (Decisão em Plenário da Suprema Corte, Era Shouwa 34.12.16, Repositório Jurisprudencial Criminal da Suprema Corte $\mathrm{n}^{\circ} 13.13 .3225$, tradução livre). 
Em sua defesa os dois irmãos alegaram que a expressão "outro instrumento de defesa ou equivalente" não se aplica às linhas de comunicação, e incidentalmente, pediram pelo reconhecimento da inconstitucionalidade do Jieitai por violação do art. $9^{\circ}$ da Constituição, de forma que a lei que tipificou como crime seus atos também seria inconstitucional. Novamente o argumento central do pedido foi a proibição da manutenção de potencial de guerra.

Os irmãos foram absolvidos em primeira instância. No que tange à questão referente ao art. $9^{\circ}$, foram aplicadas as chamadas "Ashwander Rules"23, um grupo de princípios articulados pelo Juiz Brandeis, da Suprema Corte dos Estados Unidos, para evitar seu enfrentamento. ${ }^{24}$

Em 1973, a constitucionalidade da manutenção de uma Força de Autodefesa foi novamente questionada, na forma incidental, perante o Tribunal de Sapporo, no caso Naganuma Nike. Na ocasião, para construção de uma base da força aérea do Jieitai com fins de lançamento dos Mísseis do tipo Nike-Hercules, o Ministério da Agricultura desconstituiu o status de reserva florestal de área localizada na cidade de Naganuma, Distrito Yubariguma, na ilha de Hokkaido. A população se opôs ao ato e, partindo do argumento jurídico de que, sendo as Forças de Autodefesa inconstitucionais, a desconstituição da reserva florestal também o seria, e ingressaram com ação buscando o reconhecimento da invalidade do ato administrativo. Pela terceira vez se tentou emplacar no Judiciário a ideia de que o Jieitai era inconstitucional por possuir equipamentos suficientes para configurar a manutenção de poderio bélico.

A Corte Distrital de Hokkaido proferiu decisão em primeira instância, em 1973, reconhecendo a inconstitucionalidade do Jieitai. Conforme a decisão, as Forças de Autodefesa contrariam o art. $9^{\circ}$, pois o mesmo pró́be a manutenção de qualquer potencial de guerra, inclusive defensivo, e a mera ausência formal de um exército não significa a ausência desse potencial.

Consequentemente, a base aérea contrariaria o ordenamento jurídico, já que, diante da inconstitucionalidade não é possível dizer que o cancelamento da reserva florestal está em consonância com o art. 26 do Código Florestal, segundo o qual tal cancelamento é possível na existência de interesse público relevante, pois um ato que privilegia instalação inconstitucional estaria viciado em seu motivo.

${ }^{23}$ No caso, os princípios aplicados são aqueles definidos pelo Justice Brandeis, que impedem a antecipação de decisões constitucionais quando sua análise não é fundamental na resolução do caso concreto, especialmente quando o caso pode ser resolvido com base em outros argumentos apresentados (Ashwander v. Tennessee Valley Authority 297 US 288,346; 1935).

24 札幌地判昭 $29 \cdot 3 \cdot 29$ (Corte Regional de Sapporo, Shouwa $29-3-29$ ). 
A construção da base feriria, ainda, o direito "a uma existência pacífica", presente no preâmbulo da Constituição, na medida em que uma base de "mísseis terra-ar" seria alvo primário em caso de conflito com outra nação. Além disso, a destruição da reserva colocaria o local sob a iminência de enchentes, colocando em risco a população da região. ${ }^{25}$

A decisão foi, entretanto, reformada em segunda instância pela Corte Superior de Hokkaido em 1976, utilizando o mesmo argumento do caso Sunagawa, ou seja, afirmando que o objeto de julgamento possuía alto nível de discricionariedade política, não podendo ser reconhecida inconstitucionalidade incontroversa, aplicando-se, portanto, a teoria dos atos de governo (TASHIRO; MATSUYAMA; KUZUU; MANAZURO, 1999. p. 49). Quanto ao risco de enchentes, a Corte estabeleceu a construção de uma barragem como compensação aos habitantes da região. ${ }^{26}$ A Suprema Corte rejeitou, em 1982, a apelação da decisão de segunda instância sob o fundamento de ilegitimidade ativa dos habitantes da região por falta de interesse direto na demanda. ${ }^{27}$

Ainda, o caso Hyakurikichi foi o último questionamento relevante do tema, no qual houve novamente tentativa de controle incidental de constitucionalidade o art. $9^{\circ}$. Na então cidade de Omachi, hoje Omitamashi, seria construída a base aérea Hyakuri das Forças de Autodefesa. Um grupo contrário a construção da base firmou contrato com os proprietários das terras para compra das mesmas, mas o contrato foi rescindido e as terras vendidas à Agência de Defesa (atual Ministério da Defesa).

Os antigos compradores da área ingressaram com pedido de cancelamento do registro da nova compra, cumulada com o reconhecimento do contrato original com base no art. 98, I, da Constituição, que estabelece o princípio da supremacia constitucional, a partir do qual qualquer ato que contrarie a lei fundamental não terá força legal ou validade, e, na situação concreta, a violação do ato de compra estaria configurada pela inconstitucionalidade das Forças de Autodefesa. Se as Forças são inconstitucionais, não é possível celebrar ato jurídico de compra e venda de imóvel para sua utilização. Aqui o argumento de inconstitucionalidade proposto foi diferente das situações anteriores, na medida em que não se baseou apenas na alegação de que Jieitai violava a proibição da manutenção de potencial bélico, mas também que contrariava a suposta renúncia até mesmo ao direito de autodefesa.

25 札幌地判昭48 - 9 7、判時712 - 249 (Corte Distrital de Sapporo, Shouwa 48.9.7, Publicado sob n⿳0 712.249). 27.8.117).

26 札幌高判昭 $51 \cdot 8 \cdot 5$ 、行裁例集 $27 \cdot 8 \cdot 117$ (Corte Distrital de Sapporo, Shouwa 51.8.5, $\mathbf{n}^{\circ}$ 27 最一小判昭57・9・9、民集36・9・1679 (Suprema Corte, Shouwa 57.9.9, nº 36.9.1679). 
Em 1977, a Corte Distrital de Mito negou que o art. $9^{\circ}$ renunciasse ao direito de autodefesa, e, não podendo ser averiguar de forma definitiva o "potencial de guerra" do Jieitai, sua inconstitucionalidade não poderia ser objeto da demanda. Aplicando a teoria dos atos de governo, absteve-se de declarar a inconstitucionalidade. Prejudicado o mérito da ação, a mesma foi julgada improcedente. Em 1981, a Corte de Tokyo manteve a decisão, afirmando não haver possibilidade de qualquer pronunciamento acerca da constitucionalidade do Jieitai, seja pela dificuldade de aferir o potencial de guerra, seja pela sua natureza discricionária. Por fim, da mesma forma decidiu a Suprema Corte em 1989, dando fim à controvérsia nos tribunais japoneses.

\section{CONSIDERAÇÕES FINAIS}

Após a análise aqui apresentada, é lícito observar as diversas visões que pautaram a leitura da cláusula pacifista. A primeira, e mais extrema delas, diz respeito a uma renúncia tão extensa que levou ao debate quanto à possibilidade ou não de o Japão se defender de invasões estrangeiras.

Ainda que tal interpretação não tenha prevalecido, ela serve como ponto de partida para uma série de discussões que vão desde a definição dos conceitos e expressões utilizados na redação até os limites das proibições e permissões que se depreendem de sua leitura e interpretação. A discussão no campo político parece prevalecer sobre argumentos jurídicos relacionados, de tal forma que é possível identificar até mesmo alguma deficiência técnica na forma como os próprios juristas lidaram com o assunto.

Embora a influência política na interpretação do dispositivo pacifista seja relevante, não é possível negar que a interpretação restritiva oficial é plenamente compreensível do ponto de vista jurídico, e apesar de todas as contradições aparentes, isso se dá a partir de um complexo uso de diversas técnicas de interpretação para legitimar uma realidade que dificilmente poderia ser transformada, qual seja, a necessidade de um poder armado como garantia de soberania de uma nação. Há, portanto, que garantir a existência de forças armadas para o fim de autodefesa.

É importante consignar que, apesar da vasta argumentação material travada dentro dos Poderes Executivo e Legislativo, o Judiciário, teoricamente defensor da Constituição, evitou de todas as formas apreciar o mérito da questão, e quando o fez, apresentou nas instâncias superiores decisões deficientes e pouco conclusivas. Entender se é uma demonstração exemplar de independência dos Poderes ou se é submissão do Poder mais fraco aos outros dois demanda um estudo aprofundado do tema, mas parece revelar que a inatividade do Judiciário prejudica o aperfeiçoamento do debate em torno do pacifismo japonês e, em alguma medida, contribuiu para o esvaziamento da norma pacifista. 
Além disso, no campo do Direito Internacional, verifica-se que, enquanto todos os Estados não aderirem a tratado que declare a guerra proscrita - o que não se verá, certamente, tão cedo -, impossível renunciar o direito à guerra que inclua a renúncia à autodefesa. Se autodefender é direito que permanece enquanto houver riscos latentes à soberania de algum Estado.

\section{REFERÊNCIAS}

COLEGROVE, Kenneth. The japanese constitutions. In: The American Political Science Review, v. 31, n. 6, dec. 1937, p. 1027. Disponível em: http://www.jstor.org/stable/1948956. Acesso em: 7 jun. 2011.

ITSUNOMIYA, Shizuo. Kenpou Daikyuujou no Hennsen to Kaishaku. Tóquio: Yuushindou, 1969.

KADES, Charles L. The american role in revising Japan's Imperial Constitution. Political Science Quarterly, v. 104, n. 2, Summer, 1989. Disponível em: < http://www.jstor.org/stable/2151582 >. Acesso em: 13 jun. 2012.

KASUYA, Susumu. Kenpou Kyuujou to Jieiken. Tóquio: Hougakushouin, 1986.

KENPOU CHOUSAKAI. Discurso proferido por Hitoshi Ashida na Comissão de Investigação Constitucional. Sangiinjimushouhen. Teikokukenpoukaiseishingiroku (Sensouhoukihen). Tóquio: Shin Nihon Houki Shuppan, 1952.

KOBAYASHI, Takeshi. Youkoso Nihonkokukenpou. Tóquio: Hougakushoin, $7^{\mathrm{a}}$ ed., 2006.

MAKI, John M. The Constitution of Japan: pacifism, popular sovereignty, and fundamental human rights. In: Law and Contemporary Problems, v. 53, n. 1, The Constitution of Japan: The Fifth Decade: [Part 1], p. 73-87. Estados Unidos: Duke University of Law, 1990.

McNELLY, Theodoro. The renunciation of war in the Japanese Constitution. In: Political Science Quarterly, v. 77, n. 3, set. 1962. Disponível em: <http://www.jstor.org/stable/2146310 >. Acesso em: 20 set. 2012.

NISHI, Osamu. Jieiken, Japão: Gakuyou, 1978.

SATOU, Isao. Kenpou (Jou) (Poketto Chuushaku Kensho).Tokyo: Yuuhikaku, 2001.

SUZUKI, Yasuzou. Kenpougakugenron. Tóquio: Keisoshobou, 1956.

TAKANO, Yuuichi. Kenpoudaikyuujou Kokusaihouteki ni Mita Sensouhoukijoukou. Tóquio: Yuuhikaku, 1964.

TANAKA, Hideo. Kenpouseiteikateioboesho. Tóquio: Yuuhikaku, 1987.

TASHIRO, Kikuo; MATSUYAMA, Chuuzou; KUZUU, Eijirou; MANAZURO, Toshiki. Kenpou kara kangaeru: Heiwa to Jinken. Tóquio: Houritsu Bunka, 1999.

WARD, E. Robert. The Comission on The Constitution and Prospects for Constitucional Changes in Japan. The Journal of Asian Studies, v. 24, n. 03, May. 1965. Disponível em: $<$ http://www.jstor.org/stable/2050343>. Acesso em: 13 jun. 2011.

YASUZAWA, Kiichirou. Kisou oyobi seitei no jijitsu ni rikkyakushita kenpoudaikyuujou no kaishaku. Tóquio: Seibundou, 1981. 